\title{
PENGARUH INSENTIF DAN PENGAWASAN TERHADAP KINERJA KARYAWAN PADA PT. PERKEBUNAN NUSANTARA VII (PERSERO) LAMPUNG SELATAN
}

\author{
Nuzleha $^{1}$, Yuliana Yamin, ${ }^{2}$ Meilinda Safitri ${ }^{3)}$, Tiar Mirnasari $^{4}$ \\ Universitas Sang Bumi Ruwa Jurai \\ nuzlehahadjar1970@gmail.com ${ }^{1}$,yuliyamin0607@gmail.com ${ }^{2}$,meilindasafitridian@gmail.com³, \\ tiarmirnasari2020@gmail.com ${ }^{4}$
}

\begin{abstract}
Abstrak
Objek penelitian ini adalah PT. Perkebunan Nusantara VII (Persero) Unit Usaha Pematang Kiwah Natar Kabupaten Lampung Selatan berlokasi di Jalan Raya NatarNo. 71. A.Desa Tanjungrejo, Kecamatan Natar, Kabupaten Lampung Selatan. Menghasilkan produk agribisnis dan agroindustri karet remah berkualitas Standard Indonesian Rubber (SIR) untuk pasar domestik maupun International Tujuan penelitian adalahuntuk mengetahui, pengaruh insentif terhadap kinerja karyawan padaPT. Perkebunan Nusantara VII (Persero) Unit Usaha Pematang Kiwah Natar Kabupaten Lampung Selatan, pengaruh pengawasan terhadap kinerja karyawan, untuk mengetahui pengaruh insentifdan pengawasan terhadap kinerja karyawan. Besaran sampel penelitian yang digunakan adalah 70 orang karyawan. Metode analisis dalam penelitian ini adalah kualitatif dan kuantitatif menganalisis data menggunakan rumus regresi linier berganda dan pengujian hipotesis uji t student dan uji $F$ serta didukung oleh program sofware SPSS 21.
\end{abstract}

Kata kunci ; insentif, pengawasan dan kinerja

\section{Abstract}

Object this research is PT.Plantation Nusantara VII ( persero ) business unit Pematang Kiwah Natar Kabupaten Lampung South located on the road natar no. 71.A. Tanjungrejo village, Kecamatan Natar, Kabupaten Lampung South . Produces product agribusiness and agroindustry rubber crumb quality standard indonesian rubber (sir) for market Domestic and International. Research objectives is to know, the influence of incentives to of employee performance pada PT. Plantation Nusantara VII (persero) business unit Pematang Kiwah Natar Kabupaten Lampung South, the influence of supervision of employee performance, to know the influence of incentives and oversight of employee performance. The sample the used is 70 employees. The method of analysis in this research was qualitative and quantitative analyzed data using formulas linear regression multiple and the testing of hypotheses test $t$ student and the f supported by the program sofware spss 21 .

Keywords; incentives, supervision and performance

\section{PENDAHULUAN}

Keberhasilan suatu usaha, baik bergerak pada bidang industri maupun jasa kemudian berkembang menjadi perusahaan besar, dikarenakan ada kontribusi yang besar dari pemanfaatan sumber daya manusia dalam melaksanakan kegiatan operasional rencana suatu usaha terhadap sumber-sumber lain.

Semakin besar perusahaan mengelola usahanya, maka masalah sumber daya manusia juga semakin besar dan kompleks, untuk memperkecil berbagai permasalahan yang akan timbul, maka personalia harus menyusun rencana program pengembangan sumber daya manusia, bermateri ilmu pengetahuan dan keterampilan. Hasilnya diharapkan dapat membantu para pengambilan keputusan menganalisis permintaan ke depan termasuk teknologi, persaingan dan perbandingan resiko maupun akibat ekonomis dari masing-masing alternatif rencana akan dilaksanakan maupun telah dilaksanakan. 
Di era globalisasi ekonomi saat ini berdampak sangat besar di semua sisi kehidupan masyarakat, kondisi demikian, mengharuskan individu maupun perusahaan beradaptasi dengan teknologi serta pemanfaatannya sebagai sarana kerja, pemasaran dan pengawasan.

Pengawasan akan lebih efektif dalam rangka pelaksanaan pekerjaan, diperlukan motivasi, agar gairah atau semangat kerja karyawan meningkat serta secara sadar bersedia mentaati semua peraturan sesuai dengan rencana kerja. Salah satu indikator pendukung prestasi kerja karyawan adalah dengan cara memenuhi kebutuhannya, secara adil dan layak, berupa gaji tetap dan insentif bersifat tambahan.

PT. Perkebunan Nusantara VII (Persero) Unit Usaha Pematang Kiwah berlokasi di Jalan Raya Natar No. 71. A Desa Tanjungrejo, Kecamatan Natar, Kabupaten Lampung Selatan, adalah perusahaan agribisnis dan agro industri karet berkualitas, berjenis standard Indonesian Rubber (SIR $10 \& 20$ ) Target produksi 850 ton setiap bulannya untuk pasar domestik maupun International. Berkantor pusat direksi di Jalan Teuku Umar No. 300 Kedaton Bandar Lampung.

PT. Perkebunan Nusantara VII (Persero) Unit Usaha Pematang Kiwah Natar dengan jumlah karyawan sebanyak 230 orang. Sebagian besar berasal dari masyarakat di sekitar perusahaan, kegiatan recruitment masih menggunakan sistem metode tertutup, masih bersifat kekeluargaan.

Kelebihan menggunakan sistem metode tertutup, karyawan lebih mudah beradaptasi dengan lingkungan kerja. Kelemahannya pelamar lebih sedikit, kurang selektif sesuai bidang pekerjaan, sehingga personalia belum menjamin kedisiplinan dan kesadaran berprestasinya baik.

Kondisi demikian akan berakibat menyulitkan peran pengawasan menjadi kurang efektif mencegah kesalahan, penyimpangan, ketidaksesuaian rencana yang telah ditentukan mencegah kesalahan penyimpangan, ketidaksesuaian rencana yang telah ditentukan, daya dorong yang dapat mempengaruhi kinerja karyawan menjadi relatif baik adalah insentif bersifat material maupun non material yang diberikan perusahaan.

Menurut Sarwoto, (2012 : 144) insentif adalah sebagai suatu sarana pendorong semangat kerja yang diberikan dengan sengaja kepada para pekerja, agar pada diri mereka timbul semangat yang lebih besar untuk berprestasi bagi organisasi.

Target produksi karet remah 850 ton yang ditetapkan perbulan dapat tercapai sangat tergantung dari kinerja masing-masing karyawan pada PT. Perkebunan Nusantara VII (Persero) Unit Usaha Pematang Kiwah Natar, Karena bersifat individu, seperti ; latar belakang pendidikan dan keterampilan, kepuasan kerja, kompensasi dan lainnya.

Menurut Luthans, (2014 : 62) kinerja adalah menilai bagaimana seseorang telah bekerja dibandingkan dengan ketentuan target, merupakan perilaku nyata sebagai prestasi kerja yang dihasilkan sesuai dengan perannya dalam perusahaan.

Pemutasian berlandaskan ilmiah, objektif dan hasil prestasi kerjanya baik, seperti ; tingkat tingkat kedisiplinan, semangat kerja, output produktivitas kerjanya (merit system) perlu dilakukan untuk meningkatkan kinerja.

Pemutasian karyawan pada PT. Perkebunan Nusantara VII (Persero) Unit Usaha Pematang Kiwah Natar Kabupaten Lampung Selatan atas dasar seniority system. (sumber : PTPN VII (Persero) Unit Usaha Pematang Kiwah Natar, 2016).

Permasalahan yang tergambarkan dalam latar belakang PT. Perkebunan Nusantara VII (Persero) Unit Usaha Pematang Kiwah Natar Kabupaten Lampung Selatan terkait pemberian insentif, pengawasan maupun kinerja karyawan masih bersifat sementara. Diperlukan penelitian lanjutan, agar dapat diketahui hasil penelitian melalui uji korelasi masing-masing variabel $\mathrm{X}^{1}$ dan $\mathrm{X}^{2}$ maupun secara parsial. 


\section{METODOLOGI PENELITIAN}

\section{A. Jenis Penelitian}

Jenis penelitian ini adalah survey atau riset dilapangan untuk mendapatkan data data, melalui wawancara secara terbuka dan penyebaran kuesioner sebagai sarana pengumpul data sampel dari populasi atau seluruh karyawan pada PT. Perkebunan Nusantara VII (Persero) Unit Usaha Pematang Kiwah, berlokasi di Jalan Raya Natar No. 71. A Desa Tanjungrejo, Kecamatan Natar, Kabupaten Lampung Selatan. Penelitian ini menggunakan pendekatan analisis kualitalif dan kuantitatif.

\section{B. Definisi Operasional}

Definisi operasional adalah merupakan indikator dari masing-masing variabel penelitian, data yang relevansi, terarah sesuai dengan metode pengukuran.

Menurut Singarimbun dan Effendi (2010 : 167) definisi operasional adalah petunjuk bagaimana suatu variabel diukur dengan cara membaca definisi operasional penelitian, maka akan diketahui baik buruknya variabel tersebut.

\section{Indikator Variabel}

- Insentif $\left(\mathrm{X}_{1}\right)$ :

1. Kinerja

2. lama masa kerja,

3. senioritas,

4. kebutuhan

5. keadilan dan kelayakan.

- Pengawasan $\left(\mathrm{X}_{2}\right)$ :

1. Pengawasan langsung,

2. pengawasan tidak langsung.

- Kinerja karyawan (Y).

1. Kualitas,

2. kuantitas,

3. ketepatan waktu,

4. efektivitas,

5. kemandirian.

\section{Indikator Pengukuran}

\begin{tabular}{lrlc}
\hline NO & VARIABEL & \multicolumn{1}{c}{ INDIKATOR } & $\begin{array}{c}\text { SKALA } \\
\text { PENGUKURAN }\end{array}$ \\
1. & Insentif & $\begin{array}{l}\text { Kinerja. lama kerja, } \\
\text { senioritas keadilan dan } \\
\text { kelayakan, evaluasi } \\
\text { jabatan }\end{array}$ & \\
& & $\begin{array}{l}\text { Pengawasan langsung } \\
\text { Pengawasan tidak } \\
\text { langsung }\end{array}$ & Likert \\
\hline 2. & Pengawasan &
\end{tabular}


Seminar Nasional Penelitian dan Pengabdian kepada Masyarakat

Universitas Sang Bumi Ruwa Jurai Tahun 2020

3. Kinerja karyawan Kualitas, kuantitas,

ketepatan waktu, efektivitas, kemandirian

\section{E. Skala Pengukuran}

Data penelitian diperoleh dari hasil jawaban kuesioner variabel, diukur menggunakan skala like 5 (lima), ketentuannya sebagai berikut :

Sangat Setuju (SS) skor 5

Setuju (S) skor 4

Netral (N) skor 3

Tidak Setuju(TS) skor 2

Sangat Tidak Setuju (STS) skor .

\section{Metode Penetapan Sampel dan Populasi}

Sebagaimana pendapat Sugiyono, (2012 : 147) besar sampel penelitian diambil dari sebagian populasi dan dijadikan sebagai responden menggunakan teknik tertentu.

Dengan demikian, maka penetapan sampel penelitian, diambil dari sebagian populasi pada PT. Perkebunan Nusantara VII (Persero) Unit Usaha Pematang Kiwah, menggunakan rumus Slovin:

$$
\mathbf{n}=\frac{\mathbf{N}}{\mathbf{N} \cdot \mathbf{d}^{2}+\mathbf{1}}
$$

Keterangan :

$\mathrm{n} \quad=$ Besarnya sampel

$\mathrm{N}=$ Jumlah populasi

$\mathrm{d}=$ Nilai presisi $(10 \%)$

1 = Bilangan konstan

Berdasarkan perhitungan rumus Slovin, guna untuk menentukan besaran sampel penelitian dari sebagian populasi tersebut sebagai berikut :

$$
\begin{aligned}
\mathbf{n} & =\frac{230}{230(0,1)^{2}+1} \frac{230}{230(0,01)}+1 \\
& =69,69 \approx 70 \text { Sampel }
\end{aligned}
$$

Hasil kuesioner dari masing-masing variabel penelitian terhadap 70 responden, maka akan diuji menggunakan pengujian validitas dan reliabilitas sebagai berikut:

\section{a. Uji Validitas}

Pengujian validitas dari instrument penelitian ini, dapat dilakukan menggunakan rumus korelasi product moment sebagai berikut ; 


$$
r_{x y}=\frac{n \cdot \sum X_{i} Y-\left(\sum X_{i}\right)\left(\sum Y_{i}\right)}{\sqrt{\left(n \cdot \sum X_{i}^{2}-\left(\sum X_{i}\right)^{2}\right\}\left\{n \cdot \sum Y_{i}^{2}-\left(\sum Y_{i}\right)^{2}\right\}}}
$$

Keterangan ;

$\mathrm{R}_{\mathrm{xy}}=$ Nilai

$\mathrm{X}=$ Total item variabel

$\mathrm{Y}=$ Total item variabel

$\mathrm{n}=$ Jumlah sampel diuji

Hasil perhitungan dari korelasi product moment (r hitung) tersebut, dilakukan perbandingan nilai harga kritik tabel dengan $r$ tabel, jika $r_{\text {hitung }} \geq$ nilai $r_{\text {tabel, }}$ maka item pertanyaan yang diajukan valid dan jika nilai $r$ hitung $\leq$ nilai $r$ tabel, maka item pertanyaan yang diajukan tidak valid.

Selanjutnya pengujian item pertanyaan valid atau tidak maka digunakan juga program software SPSS versi 21.

\section{b. Uji Reliabilitas}

Menurut Arikunto Suharsimi, (2010 : 93) uji reliabilitas adalah suatu kuesioner dikatakan reliabel, jika, kuesioner memiliki taraf kepercayaan yang tinggi dan memiliki kemantapan atau ketepatan.

Sedangkan untuk mengukur tingkat reliabilitas kuesioner tersebut, agar memperoleh nilai skor dari masing-masing variabel bebas $\mathrm{X}_{1}, \mathrm{X}_{2}$ dan variabel terikat Y, digunakan rumus (Cronbach Alpha), yaitu ;

$$
\alpha=\frac{K}{k-1} 1-\left(\frac{\sum \sigma^{2} I}{\sigma^{2} I}\right)
$$

Keterangan :

$$
\begin{array}{ll}
\alpha & =\text { Nilai Reliabilitas } \\
\mathrm{k} & =\text { Jumlah Item pertanyaan } \\
\sum \sigma^{2}{ }_{1} & =\text { Jumlah varians masing2 item } \\
\sigma^{2}{ }_{1} & =\text { Varians total }
\end{array}
$$

Selanjutnya setelah nilai koefisien alpha didapatkan, maka hasil $\mathrm{r}$ hitung dibandingkan dengan nilai tabel. Jika nilai alpha tabel $\geq \mathrm{r}$ hitung, maka pertanyaan tersebut reliabel. Sebaliknya jika nilai alpha $\leq \mathrm{r}$ hitung, maka pertanyaan tersebut tidak reliabel.

Pengujian selanjutnya menggunakan program software SPSS versi 21. 


\section{Metode Analisis}

\section{Analisis Kualitatif}

Data penelitian dianalisis secara kualitatif, guna mencari pemecahan masalah insentif, pengawasan dan kinerja karyawan pada PT. Perkebunan Nusantara VII (Persero) Unit Usaha Pematang Kiwah Kabupaten Lampung Selatan. Digunakan pendekatan teori manajemen sumber daya manusia dan manajemen personalia hasilnya berupa keterangan atau penjelasan.

\section{Analisis Kuantitatif}

Data penelitian dianalisis secara kuantitatif dimaksudkan adalah untuk mengetahui besaran nilai pengaruh insentif dan pengawasan terhadap kinerja karyawan, digunakan rumus regresi linier berganda sebagai berikut :

$$
\mathbf{Y}=\mathbf{a}+\mathbf{b}_{1} \mathbf{X}_{1}+\mathbf{b}_{2} \mathbf{X}_{2}+\mathbf{E t}
$$

Keterangan :

$\mathrm{Y}=$ Kinerja Karyawan

$\mathrm{X}_{1}=$ Insentif

$\mathrm{X}_{2}=$ Pengawasan

$\mathrm{a}=$ Nilai Intercep

$\mathrm{b}=$ Koefisien Regresi

$\mathrm{Et}=$ Tingkat Kesalahan $\quad($ error term $)$

Besarnya nilai pengaruh perolehan masing variabel akan di interprestasikan dengan kriteria

\section{0,801- 1,00 Sangat kuat \\ 0,601- 0,80 Kuat \\ 0,401- 0,60 Cukup kuat \\ 0,201- 0,40 Lemah \\ 0,001- 0,20 Sangat lemah}

\section{Uji Hipotesis}

Pengujian hipotesis pada setiap koefisien regresi, maka digunakan $t$ - student dengan tingkat kepercayaan $95 \%$ dan derajat kebebasan $\mathrm{df}=\left(\mathrm{nk}_{1}\right)$ dengan kriteria sebagai berikut

1. Ho ditolak dan Ha diterima, jika t hitung $>\mathrm{t}$ tabel; - $\mathrm{t}$ hitung $<-\mathrm{t}$ tabel.

2. Ho diterima dan Ha ditolak, jikat hitung < t tabel;- $t$ hitung $>-t$ tabel.

Menurut Sugiyono, (2011 : 154). Jika, Ho ditolak, berarti peubah bebas yang diuji berpengaruh nyata terhadap peubah terikat. Jika, Ho diterima berarti peubah bebas yang diuji tidak berpengaruh nyata terhadap peubah terikat

Sedangkan (Sugiyanto, 2011 : 203-212). untuk pengujian hipotesis secara keseluruhan atau pengujian koefisien determinasi $\left(\mathrm{R}_{2}\right)$, maka digunakan rumus statistic F- hitung (Fisher Test $)$ pada tingkat kepercayaan $95 \%$ danderajat kebebasan d. $\mathrm{f}_{1}=(\mathrm{k}-1)$ dan d. $_{2}=(\mathrm{n}-\mathrm{k})$ dengan kriteria pengujiannya sebagai berikut : 
1. Ho ditolak dan Ha diterima. Jika F hitung $\geq \mathrm{F}$ tabel,

2. Ho diterima dan Ha ditolak. Jika F hitung $\leq \mathrm{F}$ tabel.

Jika, Ho ditolak berarti peubah bebas yang diuji berpengaruh nyata terhadap peubah terikat. Jika, Ho diterima berarti peubah bebas yang diuji tidak berpengaruh nyata terhadap peubah terikat.

\section{HASIL DAN PEMBAHASAN}

\section{Analisis Kualitatif}

\section{Hasil Pengujian Validitas dan Reliabilitas Intrumen Penelitian}

Pengujian validitas dan reliabilitas dimaksudkan untuk mengukur tingkat kevalidan dan taraf kepercayaan, kemantapan atau ketepatan terhadap 25 pertanyaan (kuesioner), terdiri dari ; 10 pertanyaan variabel insentif $\left(X_{1}\right), 5$ pertanyaan variabel pengawasan $\left(X_{2}\right)$, dan 10 pertanyaan variabel kinerja karyawan (Y). Pengujian validitas dilakukan terhadap 70 sampel, dengan membandingkan nilai korelasi ( $\mathrm{r}$ hitung) setiap item pertanyaan (Lampiran 3) dengan nilai kritik korelasi ( $\mathrm{r}_{\text {tabel}}$ ) pada $\mathrm{df}=70$ dan taraf kepercayaan 95\% adalah 0.2319. (Lampiran 4).

Berdasarkan hasil perhitungan validitas dan realibilitas, maka dapat disajikan beberapa item pertanyaan kuisioner yang telah valid dan reliabel sebagai berikut :

Tabel 1. Data item pertanyaan yang valid dan reliable.

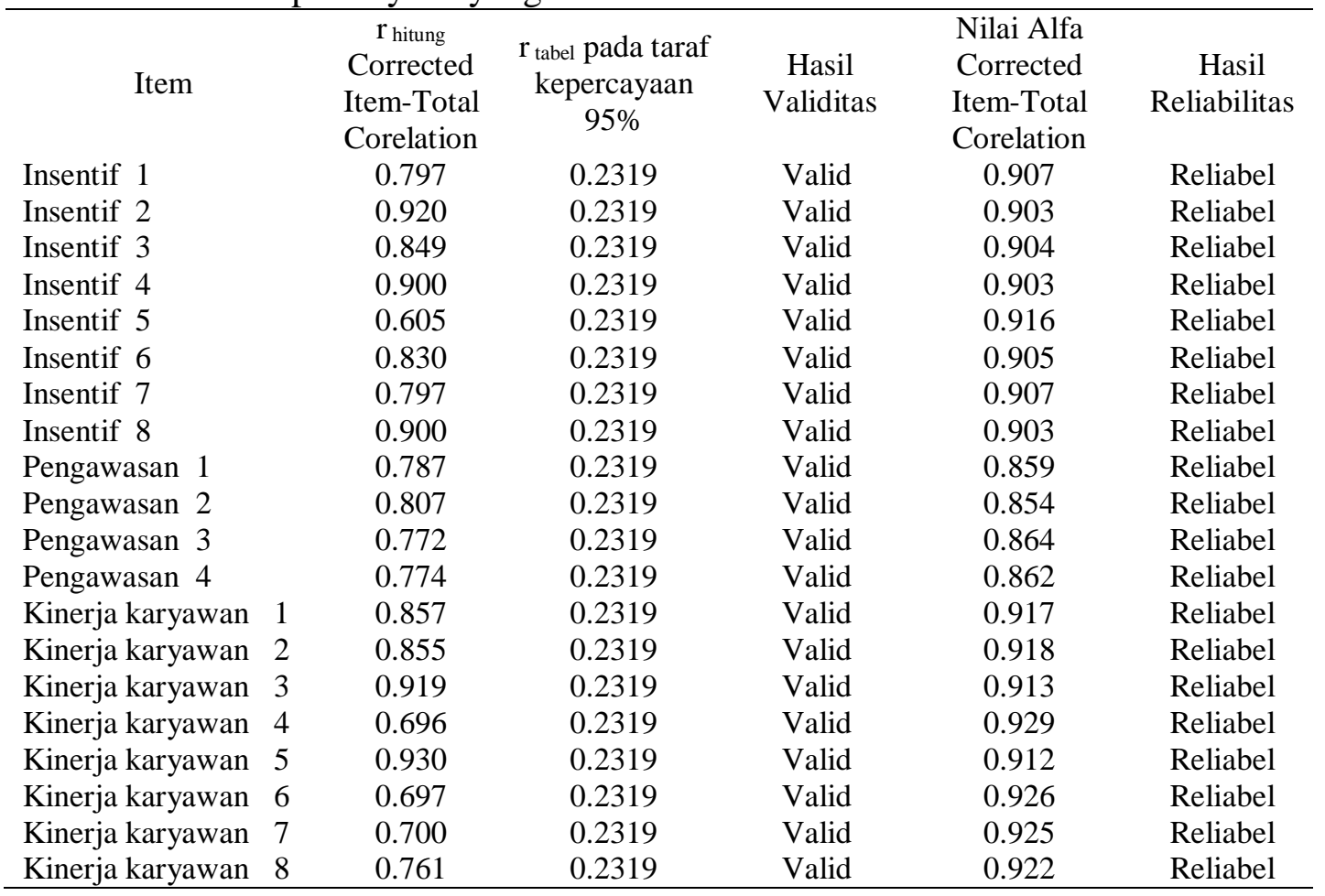

Sumber : Hasil penelitian, tahun 2019

\section{Analisis Kuantitatif}

\section{a. Pengujian Regresi Linier Berganda}

Pengujian regresi linier berganda adalah untuk mengetahui besarnya pengaruh insentif dan pengawasan terhadap kinerja karyawan pada PT. Perkebunan Nusantara VII (Persero) Unit Usaha Pematang Kiwah Natar Kabupaten Lampung Selatan. Untuk mendukung hasil penelitian digunakan program SPSS disajikan pada tabel berikut : 
Tabel 2. Hasil perhitungan regresi linier berganda, pengaruh insentif dan pengawasan terhadap kinerja karyawan

$\begin{array}{lc}\text { Statistik Regresi Linier Ganda } & \text { Nilai } \\ \text { Constanta Intercept }(a) & 5,516 \\ \text { Koefisien regresi variable } \mathrm{X}_{1},\left(\mathrm{~b}_{1} \mathrm{X}_{1}\right) & 0.714\left(\mathrm{X}_{1}\right) \\ \text { Koefisien regresi variable } \mathrm{X}_{2},\left(\mathrm{~b}_{2} \mathrm{X}_{2}\right) & 0.722\left(\mathrm{X}_{2}\right) \\ \text { Persamaan regresi } & \mathrm{Y}=5,516+0.714 \mathrm{X}_{1}+0.722 \mathrm{X}_{2} \\ \mathrm{R}(\text { Correlation }) & 0.758 \\ \mathrm{R}^{2}(R \text { Square }) & 0.574 \\ \mathrm{~F}_{\text {Hitung }} & 24.47 \\ \mathrm{~F}_{\text {Tabel }} \text { taraf Signifikan } 95 \% & 3.15 \\ \text { Df }_{1} \text { Uji F }(\mathrm{k}-1)=(3-1) & 2 \\ \text { Df }_{2} \text { Uji F }(\mathrm{n}-\mathrm{k})=(70-3) & 67\end{array}$

Sumber : Hasil penelitian, tahun 2019

Berdasarkan data tabel 2 hasil perhitungan regresi linier berganda, dapat dijelaskan sebagai berikut :

a) Persamaan Regresi Linier Berganda

Tabel 2 hasil perhitungan persamaan regresi linier berganda menunjukkan bahwa $\mathrm{Y}=5,516+0.714 . \mathrm{X}_{1}+\mathrm{e}$. Maka pengaruh dari masing-masing variabel independent (insentif dan pengawasan) terhadap variabel dependent (kinerja karyawan) bernilai positif, artinya : apabila pemberian insentif dan pengawasan ditingkatkan, maka kinerja karyawan juga akan mengalami peningkatan.

b) Koefisien Korelasi

Besarnya nilai pengaruh variabel insentif dan pengawasan terhadap kinerja karyawan ditunjukkan oleh nilai $\mathrm{R}$ (correlation), yaitu ; 0.758 atau 75,8\% (masuk dalam kriteria kuat / tinggi). Pengaruh tersebut adalah bernilai positif, artinya ; nilai variabel insentif dan pengawasan berpengaruh terhadap kinerja karyawan.

c) Koefisien Determinasi

Besarnya pengaruh insentif dan pengawasan terhadap kinerja karyawan pada PT. Perkebunan Nusantara VII (Persero) Unit Usaha Pematang Kiwah Natar Kabupaten Lampung ditunjukkan oleh nilai $\mathrm{R}^{2}$ (R Square) adalah 0.574 atau 57,4\%. Pengaruhnya bernilai positif, artinya ; kinerja karyawan dipengaruhi secara signifikan oleh insentif dan pengawasan sebesar 57,4\%. Sedangkan sisanya sebesar $42,6 \%$ dipengaruhi oleh berbagai faktor lain yang tidak dibahas dalam peneliti.

\section{b. Pengujian Hipotesis}

Pengujian hipotesis dalam penelitian ini menggunakan Uji $\mathrm{F}$ dan Uji $\mathrm{T}$, sebagai berikut :

\section{Uji F}

Untuk menguji signifikansi atau tidak pengaruh, insentif dan pengawasan terhadap kinerja karyawan secara bersama-sama membandingkan nilai $\mathrm{F}_{\text {hitung }}$ dengan $\mathrm{F}$ Tabel pada taraf signifikan $95 \%$. Ketentuan, jika $\mathrm{F}_{\text {hitung }}>\mathrm{F}_{\text {Tabel, }}$ maka ada pengaruh, jika 
$\mathrm{F}_{\text {hitung }}<\mathrm{F}$ Tabel, maka tidak ada pengaruh. Hasil pengujian hipotesis menggunakan Uji F tersebut dapat dilihat pada tabel 3 berikut :

Tabel 3. Hasil pengujian hipotesis dengan Uji $\mathrm{F}$

\begin{tabular}{|c|c|c|c|}
\hline Variabel & $F_{\text {hitung }}$ & $F$ tabel $(95 \%)$ & Kesimpulan \\
\hline Insentif $\left(\mathrm{X}_{1}\right)$ & & & $\begin{array}{l}\text { Ada pengaruh } \\
\text { signifikan insentif }\end{array}$ \\
\hline $\begin{array}{l}\text { Pengawasan }\left(\mathrm{X}_{2}\right) \\
\text { Kinerja karyawan }(\mathrm{Y})\end{array}$ & 24,47 & 3,15 & $\begin{array}{l}\text { dan pengawasan } \\
\text { terhadap kinerja } \\
\text { karvawan. }\end{array}$ \\
\hline
\end{tabular}

Sumber : data penelitian olahan, tahun 2019

Berdasarkan tabel 3 diketahui bahwa $F_{\text {hitung }}$ adalah 24,473 dan $\mathrm{F}_{\text {Tabel }}, \mathrm{Df}_{1}=2, \mathrm{Df}_{2}$ $=67$, taraf signifikan $5 \%$ adalah 3.15, maka perbandingan antara $\mathrm{F}_{\text {hitung }}$ dengan $F_{\text {Tabel }}$ pada taraf signifikan $95 \%$ adalah $F_{\text {hitung }} 24,47>F_{\text {Tabel }} 3,15$. Dengan demikian insentif dan pengawasan secara signifikan berpengaruh terhadap kinerja karyawan.

\section{Uji T}

Uji t dilakukan untuk menguji hipotesis pengaruh insentif dan pengawasan terhadap kinerja karyawan secara terpisah, membandingkan nilai $t$ hitung dengan $t$ Tabel, taraf signifikan $95 \%$. Ketentuan, jika $\mathrm{t}_{\text {hitung }}>\mathrm{t}$ Tabel, maka ada pengaruh, sebaliknya, jika $\mathrm{t}_{\text {hitung }}<\mathrm{t}$ Tabel, maka tidak ada pengaruh. Besarnya $\mathrm{t}_{\text {tabel, }}$ taraf signifikan $95 \%$, df $=70$ adalah 1,667. Hasil uji t dapat dilihat pada tabel 4 .

Tabel 4. Pengujian hipotesis dengan Uji t

$$
\text { Variabel } \quad t \text { Hitung } t \text { Tabel }(95 \%) \quad \text { Kesimpulan }
$$

\begin{tabular}{|c|c|c|c|}
\hline $\begin{array}{l}\text { Insentif }\left(\mathrm{X}_{1}\right) \text { Terhadap } \\
\text { Kinerja karyawan }(\mathrm{Y})\end{array}$ & 6,224 & 1,667 & $\begin{array}{l}\text { Ada pengaruh } \\
\text { signifikan insentif } \\
\text { terhadap kinerja } \\
\text { karvawan }\end{array}$ \\
\hline $\begin{array}{l}\text { Pengawasan }\left(\mathrm{X}_{2}\right) \\
\text { Terhadap Kinerja } \\
\text { Karyawan }(\mathrm{Y})\end{array}$ & 11,405 & 1,667 & $\begin{array}{l}\text { Ada pengaruh } \\
\text { signifikan pengawasan } \\
\text { terhadap kinerja } \\
\text { karyawan }\end{array}$ \\
\hline
\end{tabular}

Sumber. Hasil penelitian, tahun 2019

Berdasarkan tabel 4, menunjukkan besarnya nilai $t_{\text {hitung }}$ adalah 6,224 untuk variabel insentif dan pengawasan terhadap kinerja karyawan, sedangkan nilai $t_{\text {tabel }}, \mathrm{n}=70$ pada taraf signifikan $95 \%$ adalah 1,667 . Hasil perbandingnya adalah $t_{\text {hitung }}>t_{\text {tabel }}$.

Dengan demikian masing-masing secara terpisah dapat dinyatakan bahwa pemberian insentif dan pengawasan berpengaruh secara signifikan terhadap kinerja karyawan pada PT. Perkebunan Nusantara VII (Persero) Unit Usaha Pematang Kiwah Natar Kabupaten Lampung Selatan.

Pengujian hipotesis dengan Uji $\mathrm{t}$ di atas, maka hasilnya menunjukkan bahwa kontribusi pengaruh pengawasan lebih besar dibandingkan dengan insentif. Artinya adalah kinerja karyawan kuat dipengaruhi oleh pengawasan dibandingkan pemberian insentif. 


\section{Pembahasan}

Berdasarkan hasil perhitungan data penelitian menggunakan rumus persamaan regresi linier berganda menunjukkan bahwa adalah $\mathrm{Y}=5,516+0,714 \mathrm{X}_{1}+0,722 \mathrm{X}_{2}$ maknanya ; pemberian insentif dan pengawasan berpengaruh signifikan dan positif terhadap kinerja karyawan dengan nilai pengaruhnya 57,4\%. Sisanya 42,6\% dipengaruhi oleh berbagai faktor lain di luar penelitian. Sedangkan besarnya nilai korelasi variabel insentif dan pengawasan terhadap kinerja karyawan adalah $75,8 \%$ kriteria kuat.

Hal ini bermakna bahwa, apabila perusahaan meningkatkan pemberian insentif dan meningkatkan pengawasan, maka kinerja karyawan juga akan mengalami peningkatan.

Insentif merupakan penghasilan tambahan yang diberikan oleh perusahaan kepada para karyawan bekerja melampaui ketentuan standar berprestasi. Insentif adalah bagian dari kompensasi secara langsung sebagai penghargaan dalam bentuk finansial atau non finasial kepada para karyawan selain gaji dan salah satu faktor yang mempengaruhi kinerja karyawan.

Tanggapan responden mengenai insentif pada PT. Perkebunan Nusantara VII (Persero) Unit Usaha Pematang Kiwah Natar Kabupaten Lampung Selatan. Hasilnya menunjukkan bahwa sebagian besar karyawan mendapatkan bonus dan tunjangan, mendapatkan tunjangan kesehatan, mendapatkan tunjangan pensiun, mendapatkan upah lembur dan mendapatkan tunjangan hari raya atau bonus setiap tahun.

Berdasarkan hasil perhitungan regresi linier berganda menunjukkan bahwa pengawasan memberikan kontribusi pengaruh yang lebih besar dibandingkan dengan insentif. Hal ini mengandung makna bahwa salah satu faktor efektif untuk meningkatkan kinerja karyawan pada PT. Perkebunan Nusantara VII (Persero) Unit Usaha Pematang Kiwah Natar Kabupaten Lampung Selatan adalah sangat dipengaruhi oleh pengawasan.

Tanggapan responden terhadap kinerja karyawan sebagian besar karyawan bekerja sesuai dengan standar mutu, memiliki ketelitian dan tanggung jawab dalam melaksanakan pekerjaan perusahaan.

Selanjutnya sebagian karyawan bekerja dengan baik dan menghasilkan jumlah yang banyak, dapat menyelesaikan tugas dengan tepat waktu. Mampu beradaptasi dengan rekan dan lingkungan kerja. Tetapi sebagian karyawan menganggap dirinya kurang dapat menyelesaikan pekerjaan sesuai dengan ketentuan dan target yang ditetapkan serta kurang memahami dan mengetahui secara baik bidang tugas yang akan dikerjakan.

Berdasarkan hasil penelitian di atas, menunjukkan bahwa insentif dan pengawasan berpengaruh positif secara signifikan terhadap kinerja karyawan pada PT. Perkebunan Nusantara VII (Persero) Unit Usaha Pematang Kiwah Natar Kabupaten Lampung Selatan.

\section{KESIMPULAN DAN SARAN}

Berdasarkan hasil penelitian dan pembahasan maka dapat disimpulkan sebagai berikut: 
1. Pemberian insentif berpengaruh signifikan terhadap kinerja karyawan pada PT. Perkebunan Nusantara VII (Persero) Unit Usaha Pematang Kiwah Natar Kabupaten Lampung Selatan dengan besaran nilai 71, $4 \%$.

2. Pengawasan berpengaruh positif terhadap kinerja karyawan pada PT. Perkebunan Nusantara VII (Persero) Unit Usaha Pematang Kiwah Natar Kabupaten Lampung Selatan dengan besaran nilai $72,2 \%$.

3. Insentif dan pengawasan secara bersama-sama berpengaruh signifikan terhadap kinerja karyawan pada PT. Perkebunan Nusantara VII (Persero) Unit Usaha Pematang Kiwah Natar Kabupaten Lampung Selatan dengan besaran nilai 57,4\%.

\section{DAFTAR PUSTAKA}

Arikunto Suharsimi. (2011). Manajemen Penelitian. Jakarta : Penerbit Ghalia.

Dharma. (2012). Manajemen Sumber Daya Manusia. Yogyakarta: Amara Book

Handayaningrat. (2012). Manajemen Sumber Daya Manusia. Jakarta : Ghalia Indonesia

Hasibuan SP Malayu. (2012). ManajemenSDM Dasar danKunci Keberhasilan. Jakarta: Gunung Agung

. (2011). Manajemen Sumber Daya Manusia. Jakarta: Bumi Aksara

Kusnadi. (2010). Pengaruh Kedisiplinan Terhadap Kinerja. Jakarta: PT Grasindo Luthans. (2010). Organizational Behavior. The McGraw- Hill Co.I

nc. New York

Mangkunegara Prabu Anwar. (2011) . Sumber Daya Manusia. Rosda. Bandung.

Nitisemito S Alex. (2011). Manajemen Personalia dan Manajemen Sumber Daya Manusia, Ghalia Indonesia. Jakarta.

PT. Perkebunan Nusantara VII (Persero), Unit Usaha Pematang Kiwah Natar. (2015) Bandar Lampung (Lampung).

Robbins. (2012). Perilaku Organisasi : Konsep, Kontroversi, Aplikasi. Prenhillindo. Jakarta.

Sarwoto. (2012). Manajemen Personalia dan Manajemen Sumber Daya Manusia. Jakarta: Ghalia Indonesia. Jakarta.

Siagian P Sondang. (2011). Manajemen Terapan Dalam Organisasi, Yogyakarta : Rajawali Press . (2010). Manajemen Sumber Daya Manusia. Bandung : Pustaka Setia

Amrin. (2012). Populasi dan Sample Penelitian, Erlangga, Jakarta

Sugiyono. (2008). Manajemen Personalia dan Manajemen Sumber Daya Manusia. Jakarta: Ghalia Indonesia 
Seminar Nasional Penelitian dan Pengabdian kepada Masyarakat Universitas Sang Bumi Ruwa Jurai Tahun 2020

Sugiyono. (2010) Metode Penelitian Administrasi. Bandung :Alfabeta

Singarimbun dan Effendi. (2008). Manajemen Sumber Daya Manusia. Bandung :Pustaka 